\title{
Cloud-based System for Real-Time Reading of Smart Meters' Data over 5G New Radio
}

\author{
Miodrag Forcan, Mirjana Maksimović, Jovana Forcan, and Srđan Jokić
}

\begin{abstract}
The potential of the combined application of Cloud computing and the fifth generation of cellular network technology (5G) in Smart Grid (SG) could be revolutionary in terms of empowering the Advanced Metering Infrastructure (AMI). The model of a real-time 5G-based communication system for remote reading of Smart Meters' data is developed and presented in this paper. Online monitoring of power demand has been performed using the Cloud-based platform ThingSpeak. The proposed 5G communication model and online monitoring function have been tested and validated using a power demand variation scenario in a well-known IEEE 13 node network. The obtained results confirm the model accuracy and reveal the potential of AMI based on realtime data transmission between Smart meters (SM) and Cloud computing platform using a 5G communication network.
\end{abstract}

Keywords - 5G, Cloud computing, Smart meter, Smart Grid.

\section{INTRODUCTION}

G REATER reliability, security, efficiency, economy, and environmental friendliness are the primary objectives of the transition from the traditional grid to the smart one. The seven characteristics define the Smart Grid (SG) [1]: the active involvement of consumers, accommodation of all generation and storage options, facilitation of new products, services or markets, provision of power quality for the digital economy, optimization of the use of assets and operating efficiency, anticipation, and response to system disturbances (self-healing), and resilience against attacks and natural disasters. The idea behind the SG vision can be summarized into the delivery of high-quality power continuously, efficiently, and securely. This can be achieved by means of heterogeneous intelligent devices (sensors and meters) and an appropriate, highly flexible, secured, and two-way communication between the transmission and distribution sectors, securing and transmitting the mass of data produced within an SG environment [2], [3]. The voluminous and various types of

Paper received May 26, 2021; revised July 23; accepted October 06, 2021. Date of publication December 30, 2021. The associate editor coordinating the review of this manuscript and approving it for publication was Prof. Zorica Nikolić.

This paper is a revised and expanded version of the paper presented at the 28th Telecommunications Forum TELFOR 2020 [5].

M. Forcan, M. Maksimović and S. Jokić are with University of East Sarajevo, Faculty of Electrical Engineering, Bosnia and Herzegovina (e-mail: miodrag.forcan@etf.ues.rs.ba,

mirjana.maksimovic@etf.ues.rs.ba, srdjan.jokic@etf.ues.rs.ba )

J. Forcan is with University of East Sarajevo, Faculty of Philosophy, Department of Mathematics, Informatics and Physics, Bosnia and Herzegovina (e-mail: jovana.forcan@ff.ues.rs.ba).
SG-produced data are usually sent to the Cloud for further processing, storage, and decision making. This task is quite challenging due to latency, locality, and network congestion [4]. The realization of the SG communication system that will enable a bi-directional exchange of data in near realtime and will satisfy SG's needs (in terms of data rate, transmission range, latency, security, adaptivity, etc.) is extremely important [5].

The vision of the modern world, established on the idea of the Internet of Things (IoT), provides an increasing need to accept information from many points in a short time. Furthermore, enabling controlled processes and features in SG requires a completely different concept of recording certain measured quantities. The phenomenon of a distributed architecture of an electrical network also contributes to this sense of approach [6]. An important role of Smart Meters (SM) is also reporting on electricity quality indicators, active and reactive power measurement, load control, fault reporting, and other power grid functional measures [7].

The fifth generation of mobile communications ( $5 \mathrm{G})$, due to its excellent performances in terms of capacity, data rate, latency, security, etc., can provide an adequate response to a wide variety of emerging applications characterized by a high connection density, very high traffic intensity and very high mobility [8]. As such, 5G mobile communication technology appears to be the perfect candidate for SG application in the process of transmitting data from many heterogeneous smart devices to a remote, centralized Cloud. The computational requirements for SG applications can be fulfilled using Cloud computing. Flexible resources and services shared across networks, parallel processing, and ubiquitous access [9] are some of the features of Cloud computing that are desirable for SG applications. The example of applying a Cloud-based communication approach in SG is demonstrated in [10].

Based on previous statements, the symbiosis between $5 \mathrm{G}$ and Cloud and its integration into SG appears to be the key solution for real-time collection and the analysis of large quantities of different kinds of data from heterogeneous devices and widely distributed geographically [5].

This paper presents the concept of integration of $5 \mathrm{G}$ communication system and Cloud computing in SG-related application scenario. The paper is organized as follows. The Cloudification concept to support online monitoring in SG is described in Section II. Section III explains the modeling of real-time communication between Cloud server and SMs. In Section IV, the online power demand monitoring in IEEE 13 node network is defined as the case study to validate the proposed real-time communication system 
model. The results of Bit Error Rate (BER) performance related to data transmission over a fading communication channel are elaborated in Section V. Section VI gives relevant conclusion remarks.

\section{CLOUDIFICATION TO SUPPORT ONLINE MONITORING OF POWER DEMAND OVER 5G NEW RADIO}

The development of $5 \mathrm{G}$ and Cloudification affects one another. 5G impacts the development of Cloud computing by making the Cloud distributed in terms of Fog and Edge computing existence that enable decentralized and intelligent processing and storage closer to the endpoints where data is being gathered and used. Data processing and storage become localized by adding data microcenters to or near 5G towers. Fog and Edge computing services reduce bandwidth use by pre-processing data more quickly and sending only relevant data further to the Cloud. Faster data streaming and analysis, working from any location through better connectivity, developing better security systems and new features are benefits that $5 \mathrm{G}$ will bring to the Cloud. To meet operational and application needs, 5G technologies move away from hardware-driven infrastructure. They are undergoing "Cloudification" through Software Defined Networking (SDN), Network Function Virtualization (NFV), network slicing, and self-managed networks [5]. The symbiosis of Cloud infrastructure and 5G communication network can be seen as the distributed Cloud environment (Central and Edge Clouds) based on SDN, NFV, and 5G technologies that enable multi-access and multi-Cloud capabilities. Extending Cloud platforms, technologies, and virtualization capabilities throughout a network, make 5G infrastructure more agile, flexible, and scalable [5], [11]-[13].

Online monitoring of power demand across power network's nodes is the most important task of AMI in SG. The main goal is to provide real-time data about the general status of the network to the Distribution System Operator (DSO) and other SG clients [14]. Real-time communications have been enabled by the most modern SM devices. 5G NR can provide high user density, reliability, and availability through enhanced Mobile Broadband (eMBB) service. Cloud computing services enable the Big Data paradigm required to process large amounts of SMs data in real-time.

\section{MODELING OF 5G-BASED REAL-TIME COMMUNICATION BETWEEN CLOUD SERVER AND SMART METERS}

An interactive model has been developed to demonstrate the real-time communication between SMs and Cloud server. Modeling and simulation were conducted using Matlab R2020a [15]. The conceptual modeling scheme is given in Fig. 1.

SM's data are generated in the form of power demands successively updating in 15-minute time intervals. MATLAB-function block is used to implement memory registers of the SM model according to [16].

Transport blocks consist of power demands per phase and event date and time information. Transport block lengths are 104 and 232 bits for single-phase and threephase SMs, respectively.

\section{A. $5 G$ Communication model}

A $5 \mathrm{G}$ communication model consists of three MATLABfunction blocks implementing a transmitter, channel, and base station. Transport blocks are coded in transmitters according to procedures recommended in the 3rd Generation Partnership Project (3GPP) [17]. Low-Density Parity-Check (LDPC) codes are recommended to be used for uplink transmission of the user's information due to their excellent BER performance and fast encoding and decoding procedures.

To simulate the influence of natural random signals on wireless signals, the AWGN (Additive White Gaussian Noise) channel can be selected in the simulation procedure. In this case, the noise is additive, white, and with a Gaussian distribution of noise samples. The AWGN channel model does not consider fading, frequency selectivity, interference, nonlinearity, or dispersion. As a result, for the realistic channel modeling for most wireless connections, the AWGN model is inadequate. As in realistic scenarios, there are a variety of propagation routes from transmitters to receivers, various forms of fading, and other related distortions were added to the emitted signal. Therefore, apart from the direct path between the transmitter and the receiver (which may not even exist), other paths can be formed by reflection, diffraction, scattering, or other propagation scenarios.

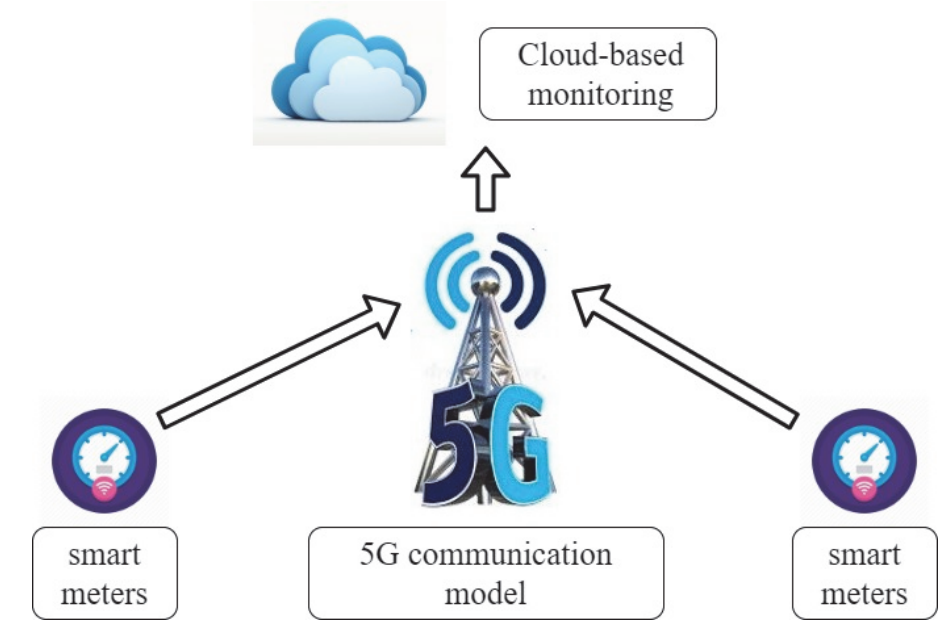

Fig. 1. Modeling of Cloud-based monitoring of Smart Meters' data over 5G NR. 
Consequently, various versions of the transmitted signal that have arrived at the receiver side have variable signal strength, time delay, or phase. The most widely used models of channels for indoor and outdoor wireless communications are Rician and Rayleigh. The Rician channel model is used where there is a dominant line-ofsight (LoS) component between the transmitter and the receiver, while a Rayleigh channel pattern is applied when there is no LoS component [18].

To model a more realistic wireless communication channel, a fading channel block was followed by the AWGN channel block.

Data from SMs are received by the base station model in regular 15-minute time intervals. After signal demodulation, transport blocks are retrieved using the decoding procedure defined in [17]. Implemented LDPC decoder uses the sum-product message-passing algorithm. The maximum number of decoding iterations is set to 25 .

\section{B. Cloud-based IoT platform ThingSpeak}

Real-time communication between MATLAB models and the Cloud platform was simulated with the help of the ThingSpeak server. ThingSpeak [19] is an IoT Cloud platform capable of simulating real-time communication, enabling a bidirectional flow of information between the user and the simulated system. ThingSpeak allows gathering and storing sensor data in the Cloud, provides analytic tools and visualization using MATLAB programming, and development of IoT applications. In this paper, a collection of real-time SMs data flows in the Cloud as well as their online analysis and visualization with MATLAB were done using the ThingSpeak platform.

Real-time software interfaces with the operating system to enable the highest priority of execution to the developed
$5 \mathrm{G}$ communication model at the prescribed sample times.

Validation of the $5 \mathrm{G}$ communication model has been performed by comparing transport blocks generated by SMs and received by ThingSpeak.

\section{REAL-TIME MONITORING OF POWER DEMAND IN IEEE 13 NODE NETWORK}

To demonstrate the functionality of the proposed approach for real-time monitoring of power demand a developed $5 \mathrm{G}$ communication model has been tested on the example of the IEEE 13 node network [20]. The previous network is often used for basic distribution system analyses, such as power flows, voltage control, renewable energy integration, etc.

\section{A. Power demand variation scenario}

Nominal demand powers for IEEE 13 nodes are given in Table 1. In nodes 634, 671 and 675 power demands are three-phase, while in the remaining nodes power demands are single-phase. The highest balanced nominal power demand is in node 671, while the highest unbalanced power demand is in node 675 . Generally, IEEE 13 node network is unbalanced.

The special power demand variation scenario has been defined as shown in Table 2. Real-time power demand monitoring has been initiated at 21:25 on May 21st. Power demand variations have been initiated in successive 15minute time intervals. Monitoring time ended at 22:10.

The power demand is constantly rising in some nodes, such as 611,634, and 692. In some nodes, such as 645, 646, and 675 , there is a fluctuation of power demand (rising and dropping).

Table 1 Nominal power demands in IEEE 13 node network

\begin{tabular}{|c|c|c|c|c|c|c|c|c|}
\hline Node number & 611 & 634 & 645 & 646 & 652 & 671 & 675 & 692 \\
\hline $\begin{array}{c}\text { Nominal } \\
\text { power } P_{\mathrm{n}}(\mathbf{k W})\end{array}$ & $170(\mathrm{C})$ & $\begin{array}{l}160(\mathrm{~A}) \\
120(\mathrm{~B}) \\
120(\mathrm{C})\end{array}$ & $170(\mathrm{~B})$ & $230(\mathrm{~B})$ & $128(\mathrm{~A})$ & $\begin{array}{l}385(\mathrm{~A}) \\
385(\mathrm{~B}) \\
385(\mathrm{C})\end{array}$ & $\begin{array}{c}485(\mathrm{~A}) \\
68(\mathrm{~B}) \\
290(\mathrm{C})\end{array}$ & $170(\mathrm{C})$ \\
\hline
\end{tabular}

Table 2 Power demand scenario in IEEE 13 node network

\begin{tabular}{|c|c|c|c|c|c|c|c|c|}
\hline \multirow[b]{2}{*}{$\begin{array}{c}\text { Smart } \\
\text { Meters }\end{array}$} & \multicolumn{8}{|c|}{ Monitoring time instants (15-minute-long time intervals) } \\
\hline & $21: 25$ & $21: 40$ & $21: 55$ & $21: 10$ & $21: 25$ & $21: 40$ & $21: 55$ & $22: 10$ \\
\hline Node 611 & $0.8 P_{\mathrm{n}}(\mathrm{C})$ & $0.8 P_{\mathrm{n}}(\mathrm{C})$ & $0.85 P_{\mathrm{n}}(\mathrm{C})$ & $0.85 P_{\mathrm{n}}(\mathrm{C})$ & $0.9 P_{\mathrm{n}}(\mathrm{C})$ & $0.9 P_{\mathrm{n}}(\mathrm{C})$ & $P_{\mathrm{n}}(\mathrm{C})$ & $P_{\mathrm{n}}(\mathrm{C})$ \\
\hline Node 634 & $\begin{array}{l}0.6 P_{\mathrm{n}}(\mathrm{A}) \\
0.6 P_{\mathrm{n}}(\mathrm{B}) \\
0.6 P_{\mathrm{n}}(\mathrm{C}) \\
\end{array}$ & $\begin{array}{c}0.65 P_{\mathrm{n}}(\mathrm{A}) \\
0.7 P_{\mathrm{n}}(\mathrm{B}) \\
0.7 P_{\mathrm{n}}(\mathrm{C}) \\
\end{array}$ & $\begin{array}{l}0.7 P_{\mathrm{n}}(\mathrm{A}) \\
0.7 P_{\mathrm{n}}(\mathrm{B}) \\
0.7 P_{\mathrm{n}}(\mathrm{C}) \\
\end{array}$ & $\begin{array}{c}0.75 P_{\mathrm{n}}(\mathrm{A}) \\
0.7 P_{\mathrm{n}}(\mathrm{B}) \\
0.7 P_{\mathrm{n}}(\mathrm{C}) \\
\end{array}$ & $\begin{array}{l}0.8 P_{\mathrm{n}}(\mathrm{A}) \\
0.8 P_{\mathrm{n}}(\mathrm{B}) \\
0.8 P_{\mathrm{n}}(\mathrm{C}) \\
\end{array}$ & $\begin{array}{c}0.85 P_{\mathrm{n}}(\mathrm{A}) \\
0.8 P_{\mathrm{n}}(\mathrm{B}) \\
0.8 P_{\mathrm{n}}(\mathrm{C}) \\
\end{array}$ & $\begin{array}{l}0.9 P_{\mathrm{n}}(\mathrm{A}) \\
0.9 P_{\mathrm{n}}(\mathrm{B}) \\
0.9 P_{\mathrm{n}}(\mathrm{C}) \\
\end{array}$ & $\begin{array}{l}P_{\mathrm{n}}(\mathrm{A}) \\
P_{\mathrm{n}}(\mathrm{B}) \\
P_{\mathrm{n}}(\mathrm{C}) \\
\end{array}$ \\
\hline Node 645 & $0.6 P_{\mathrm{n}}(\mathrm{B})$ & $0.7 P_{\mathrm{n}}(\mathrm{B})$ & $0.9 P_{\mathrm{n}}(\mathrm{B})$ & $P_{\mathrm{n}}(\mathrm{B})$ & $0.9 P_{\mathrm{n}}(\mathrm{B})$ & $0.8 P_{\mathrm{n}}(\mathrm{B})$ & $0.7 P_{\mathrm{n}}(\mathrm{B})$ & $0.6 P_{\mathrm{n}}(\mathrm{B})$ \\
\hline Node 646 & $0.9 P_{\mathrm{n}}(\mathrm{B})$ & $0.8 P_{\mathrm{n}}(\mathrm{B})$ & $0.9 P_{\mathrm{n}}(\mathrm{B})$ & $P_{\mathrm{n}}(\mathrm{B})$ & $0.9 P_{\mathrm{n}}(\mathrm{B})$ & $0.8 P_{\mathrm{n}}(\mathrm{B})$ & $P_{\mathrm{n}}(\mathrm{B})$ & $0.9 P_{\mathrm{n}}(\mathrm{B})$ \\
\hline Node 652 & $0.8 P_{\mathrm{n}}(\mathrm{A})$ & $0.8 P_{\mathrm{n}}(\mathrm{A})$ & $0.8 P_{\mathrm{n}}(\mathrm{A})$ & $0.8 P_{\mathrm{n}}(\mathrm{A})$ & $0.8 P_{\mathrm{n}}(\mathrm{A})$ & $0.8 P_{\mathrm{n}}(\mathrm{A})$ & $0.8 P_{\mathrm{n}}(\mathrm{A})$ & $0.8 P_{\mathrm{n}}(\mathrm{A})$ \\
\hline Node 671 & $\begin{array}{l}P_{\mathrm{n}}(\mathrm{A}) \\
P_{\mathrm{n}}(\mathrm{B}) \\
P_{\mathrm{n}}(\mathrm{C}) \\
\end{array}$ & $\begin{array}{l}0.95 P_{\mathrm{n}}(\mathrm{A}) \\
0.95 P_{\mathrm{n}}(\mathrm{B}) \\
0.95 P_{\mathrm{n}}(\mathrm{C})\end{array}$ & $\begin{array}{l}0.9 P_{\mathrm{n}}(\mathrm{A}) \\
0.9 P_{\mathrm{n}}(\mathrm{B}) \\
0.9 P_{\mathrm{n}}(\mathrm{C}) \\
\end{array}$ & $\begin{array}{l}0.85 P_{\mathrm{n}}(\mathrm{A}) \\
0.85 P_{\mathrm{n}}(\mathrm{B}) \\
0.85 P_{\mathrm{n}}(\mathrm{C}) \\
\end{array}$ & $\begin{array}{l}0.8 P_{\mathrm{n}}(\mathrm{A}) \\
0.8 P_{\mathrm{n}}(\mathrm{B}) \\
0.8 P_{\mathrm{n}}(\mathrm{C}) \\
\end{array}$ & $\begin{array}{l}0.75 P_{\mathrm{n}}(\mathrm{A}) \\
0.75 P_{\mathrm{n}}(\mathrm{B}) \\
0.75 P_{\mathrm{n}}(\mathrm{C}) \\
\end{array}$ & $\begin{array}{l}0.7 P_{\mathrm{n}}(\mathrm{A}) \\
0.7 P_{\mathrm{n}}(\mathrm{B}) \\
0.7 P_{\mathrm{n}}(\mathrm{C}) \\
\end{array}$ & $\begin{array}{l}0.7 P_{\mathrm{n}}(\mathrm{A}) \\
0.7 P_{\mathrm{n}}(\mathrm{B}) \\
0.7 P_{\mathrm{n}}(\mathrm{C})\end{array}$ \\
\hline Node 675 & $\begin{array}{c}P_{\mathrm{n}}(\mathrm{A}) \\
0.7 P_{\mathrm{n}}(\mathrm{B}) \\
P_{\mathrm{n}}(\mathrm{C}) \\
\end{array}$ & $\begin{array}{c}0.9 P_{\mathrm{n}}(\mathrm{A}) \\
0.75 P_{\mathrm{n}}(\mathrm{B}) \\
0.95 P_{\mathrm{n}}(\mathrm{C})\end{array}$ & $\begin{array}{c}0.8 P_{\mathrm{n}}(\mathrm{A}) \\
0.75 P_{\mathrm{n}}(\mathrm{B}) \\
0.9 P_{\mathrm{n}}(\mathrm{C}) \\
\end{array}$ & $\begin{array}{c}0.6 P_{\mathrm{n}}(\mathrm{A}) \\
0.8 P_{\mathrm{n}}(\mathrm{B}) \\
0.85 P_{\mathrm{n}}(\mathrm{C}) \\
\end{array}$ & $\begin{array}{l}0.5 P_{\mathrm{n}}(\mathrm{A}) \\
0.8 P_{\mathrm{n}}(\mathrm{B}) \\
0.8 P_{\mathrm{n}}(\mathrm{C}) \\
\end{array}$ & $\begin{array}{c}0.5 P_{\mathrm{n}}(\mathrm{A}) \\
0.85 P_{\mathrm{n}}(\mathrm{B}) \\
0.75 P_{\mathrm{n}}(\mathrm{C}) \\
\end{array}$ & $\begin{array}{l}0.5 P_{\mathrm{n}}(\mathrm{A}) \\
0.9 P_{\mathrm{n}}(\mathrm{B}) \\
0.7 P_{\mathrm{n}}(\mathrm{C}) \\
\end{array}$ & $\begin{array}{c}0.5 P_{\mathrm{n}}(\mathrm{A}) \\
P_{\mathrm{n}}(\mathrm{B}) \\
0.7 P_{\mathrm{n}}(\mathrm{C}) \\
\end{array}$ \\
\hline Node 692 & $0.5 P_{\mathrm{n}}(\mathrm{C})$ & $0.6 P_{\mathrm{n}}(\mathrm{C})$ & $0.7 P_{\mathrm{n}}(\mathrm{C})$ & $0.8 P_{\mathrm{n}}(\mathrm{C})$ & $0.9 P_{\mathrm{n}}(\mathrm{C})$ & $0.95 P_{\mathrm{n}}(\mathrm{C})$ & $P_{\mathrm{n}}(\mathrm{C})$ & $P_{\mathrm{n}}(\mathrm{C})$ \\
\hline
\end{tabular}


Constant power demand is present in node 652, and constantly dropping power demand is present in node 671 . All previously described scenarios could be expected in real distribution networks. Power demand variations could be even more dynamic in certain situations.

\section{B. Monitoring system model implementation}

The proposed monitoring system model is implemented in the simulation environment Simulink. The model consists of demand, SMs, fading channel, base station, and Cloud communication interface models. Transport blocks are sent by $8 \mathrm{SMs}$ to the base station over fading wireless communication channels. Received transport blocks are then transmitted from the base station to Cloud platform ThingSpeak. The integration of the proposed 5G communication model and IEEE 13 node network model is shown in Fig. 2.

There is no power demand in nodes $632,633,684$, and 680. The main distribution station is in node 650 . The nodes 634, 671, and 675 are equipped with three-phase SMs, while the remaining nodes are equipped with single-phase SMs. The power is delivered to end-users using power overhead transmission lines and transformers. There is a voltage regulation transformer between nodes 650 and 632 . The power demand variation scenario, defined earlier in Table 2, has been applied to the model described in Fig. 2.

DSO can monitor the power delivered from the main distribution station (node 650) remotely if there is a Supervisory Control and Data Acquisition (SCADA) system built. SCADA systems usually operate using an independent communication network, such as fiber optics infrastructure. The proposed power demand monitoring system over a $5 \mathrm{G}$ communication network could be used by DSO to estimate the power losses more accurately. Load profiling and forecasting would be also available to DSO, thus empowering the transition to the concept of SG and efficient energy management.

\section{Results of power demand online monitoring}

The selected results of power demand online monitoring in IEEE 13 node network are shown in Fig. 3.

According to monitoring results from displays (a.1), (a.2), and (a.3) in Fig. 3, there is a constant three-phase power demand dropping in node 671. Power demand has been decreasing equally in phases $\mathrm{A}, \mathrm{B}$, and $\mathrm{C}$ during monitoring time. By comparing the obtained results with the corresponding power demand variation scenario for node 671 in Table 2 it can be concluded that the online monitoring function operates accurately. All power demand values are transmitted with no errors. Monitoring time instants defined in Table 2 are coincident with time instants recorded in cloud platform ThingSpeak shown in Fig. 3. The proposed $5 \mathrm{G}$ communication system model can deliver real-time data from SM models to the Cloud platform ThingSpeak accurately, thus enabling online monitoring function.

The functionality of the proposed model can be validated additionally according to monitoring results from displays (b.1), (b.2), and (b.3) in Fig. 3. Previous displays monitor power demands in nodes 611,645 , and 646, respectively. The recorded power demands are equal to corresponding ones in the power demand variation scenario given in Table 2. The power demand in node 611 has been constantly increasing during monitoring time, while power demands in nodes 645 and 646 have been fluctuating. All power demands recorded are single-phase since SMs in the corresponding nodes are also single-phase.

The monitoring results of the remaining power demands also confirm the functionality and accuracy of the proposed model.

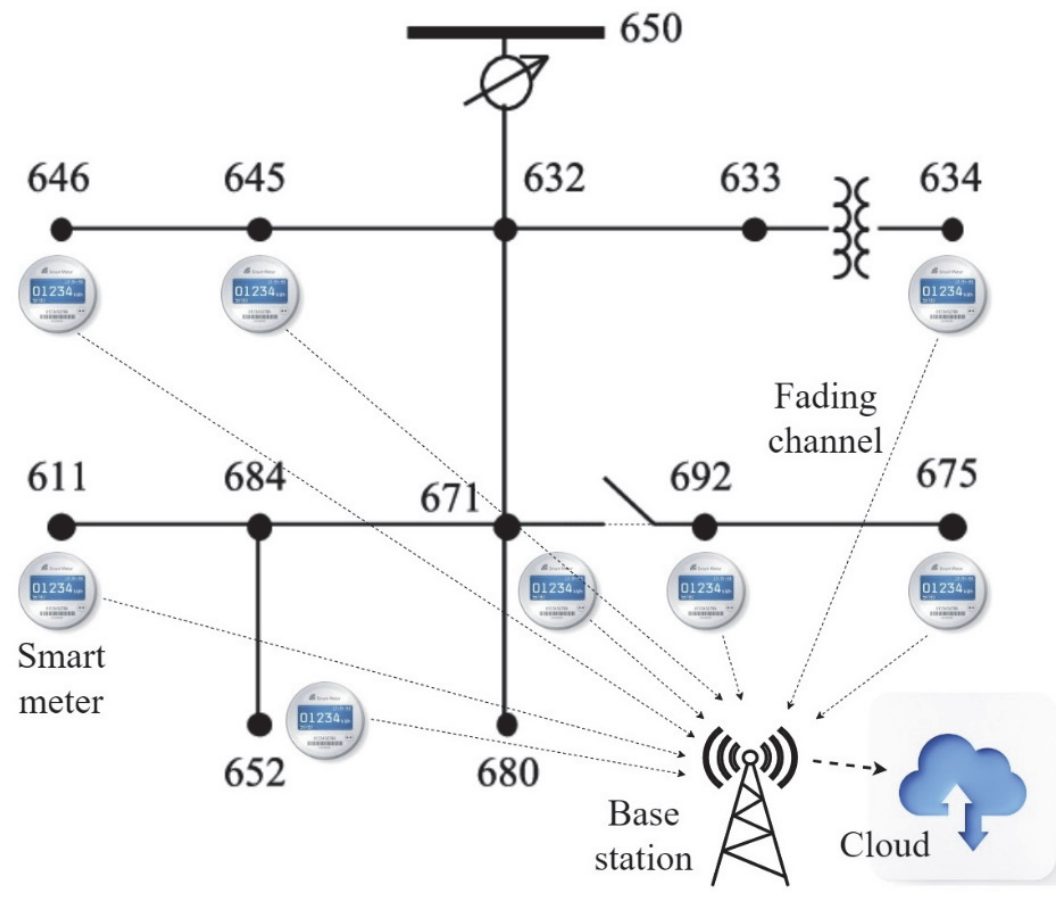

Fig. 2. Real-time monitoring of power demand from multiple Smart Meters in IEEE 13 Node Network. 
(a.1)

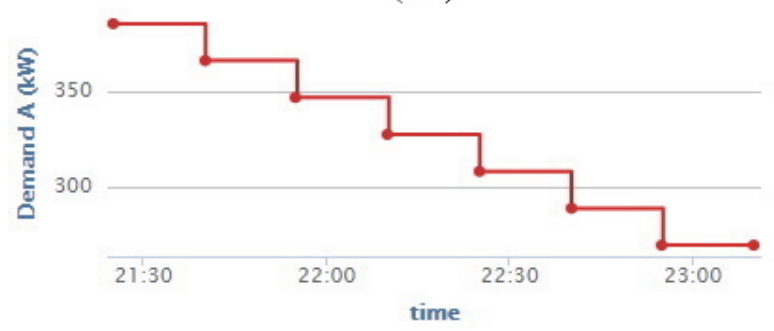

(a.2)

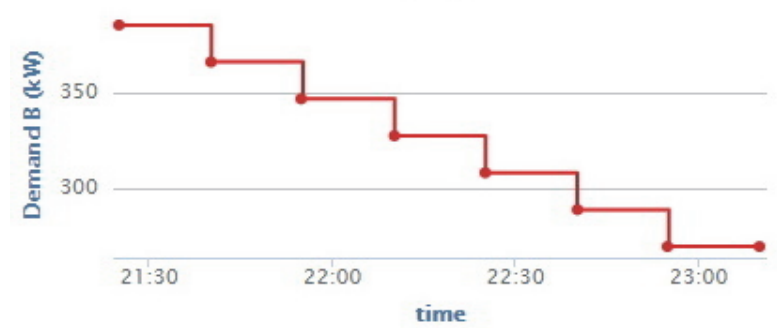

(a.3)

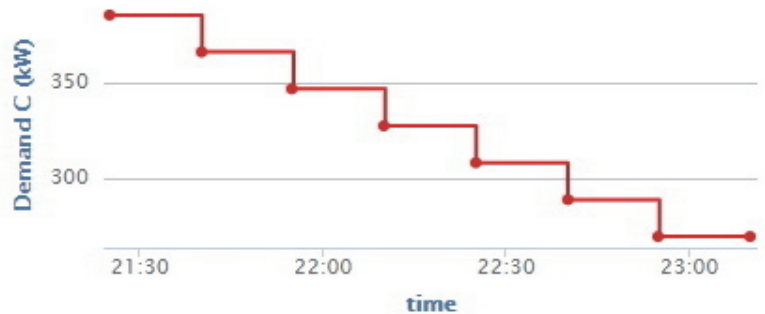

(b.1)

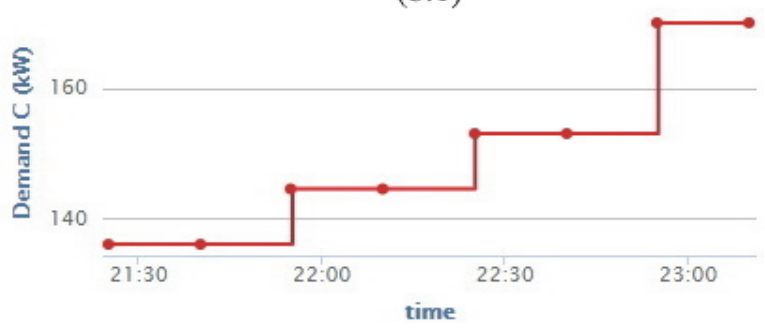

(b.2)

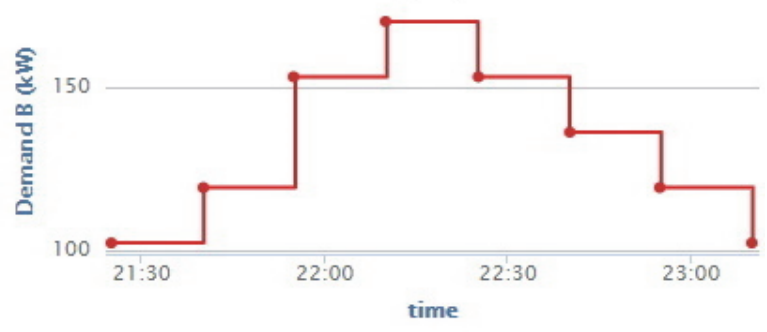

(b.3)

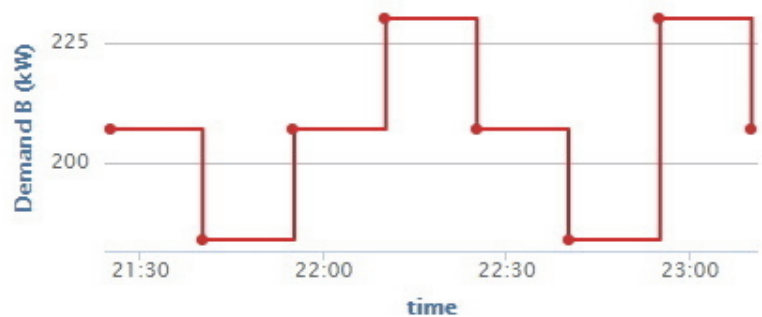

Fig. 3. Online monitoring of power demand in IEEE 13 Node Network using Cloud computing platform ThingSpeak: (a.1) SM in node 671 - phase A; (a.2) SM in node 671 - phase B; (a.3) SM in node 671 - phase C; (b.1) SM in node 611 - phase C; (b.2) SM in node 645 - phase B; (b.3) SM in node 646 - phase B.

\section{BER PERFORMANCE ANALYSIS}

To protect digital information against noise and interference on the communication channel, the transmitted digital signal is followed by a channel coding scheme. In other words, a channel coding technique is an option for reliable communication with a minimum error rate. For the SMs data transmission, LDPC coding chains for the $5 \mathrm{G}$ uplink shared transport channel UL-SCH, prescribed by 3GPP [15], were used. To evaluate the performance of the proposed system, a BER analysis was carried out. BER is the key parameter for characterizing a system performance, as it makes it possible to evaluate the end-to-end performance of a system (including the transmitter, receiver, and medium in between). As its name suggests, BER indicates how many errors will appear in the data displayed at the remote end.

For more realistic simulation scenarios, the Rayleigh channel model was used in this article. In this case, both noise (follows a Gaussian probability function) and changes to the propagation path (the propagation model follows a Rayleigh model) can result in the degradation of a data channel. Hence, during the simulation, a fading channel block was followed by the AWGN channel block. The Rayleigh channel property values are selected for the outdoor environment: Sampling Rate: $10^{5} \mathrm{~s}$; Path Delays: 0, $10^{-7}$ and $10^{-5} \mathrm{~s}$ (for outdoor environment); Average Path Gains: $0,-3$, and $-3 \mathrm{~dB}$; a maximum Doppler shift of 0 (low mobility leads to a Doppler shift of near zero).
The code rate used in simulations is $1 / 2$. Data transmission has been performed using Quadrature Phase Shift Keying (QPSK) modulation. In addition to QPSK, Physical Uplink Shared Channel (PUSCH) supports pi/2BPSK, QPSK, 16-QAM, 64-QAM, and 256-QAM modulation schemes. QPSK provides lower data rates but is more robust compared to higher-order modulation schemes that can carry higher data rates but are not as robust when noise is present.

BER simulations as a function of $\mathrm{E}_{\mathrm{b}} / \mathrm{N}_{0}$ (Energy per bit to noise power spectral density ratio) for all eight SMs messages have been performed and presented in Fig. 4. Each simulation for a fixed $\mathrm{E}_{\mathrm{b}} / \mathrm{N}_{0}$ value was performed for 500 frames. The simulation procedure was continued for the following $\mathrm{E}_{\mathrm{b}} / \mathrm{N}_{0}$ values until the calculated BER value became lower than $10^{-5}$ which is set as a reliable transmission criterion. The main goal was to determine the minimum $\mathrm{E}_{\mathrm{b}} / \mathrm{N}_{0}$ value required to achieve the reliable transmission criterion under considered conditions.

For each of the SMs transport block lengths considered, the BER vs $\mathrm{E}_{\mathrm{b}} / \mathrm{N}_{0}$ graph has a typical curve - BER decreases with the increase of $E_{b} / N_{0}$. It is important to highlight that when the BER value for some fixed $E_{b} / N_{0}$ value becomes lower than $10^{-5}$ or equal to zero it is not presented in Fig. 4. The higher accuracy of simulations could be achieved by lowering the $\mathrm{E}_{\mathrm{b}} / \mathrm{N}_{0}$ increment step value which leads to more time-consuming simulations with similar results as in the case of higher $E_{b} / N_{0}$ increment step. In addition, it can be noted that for the longer transport block lengths - 232 bits (nodes 634, 671, and 675), error correction 
requirements of desired BER values can be reached at lower $\mathrm{E}_{\mathrm{b}} / \mathrm{N}_{0}$ values, while in the case of other nodes with shorter transport block lengths, a target BER value is achieved at higher $\mathrm{E}_{\mathrm{b}} / \mathrm{N}_{0}$ values. These results confirm the LDPC superiority in the case of longer message lengths. In summary, the results demonstrate that the BER performances of LDPC codes are better for high $E_{b} / N_{0}$ values, but the reliable transmission is possible even in low $\mathrm{E}_{\mathrm{b}} / \mathrm{N}_{0}$ values, which is very unlikely in a practical applications of $5 \mathrm{G}$.

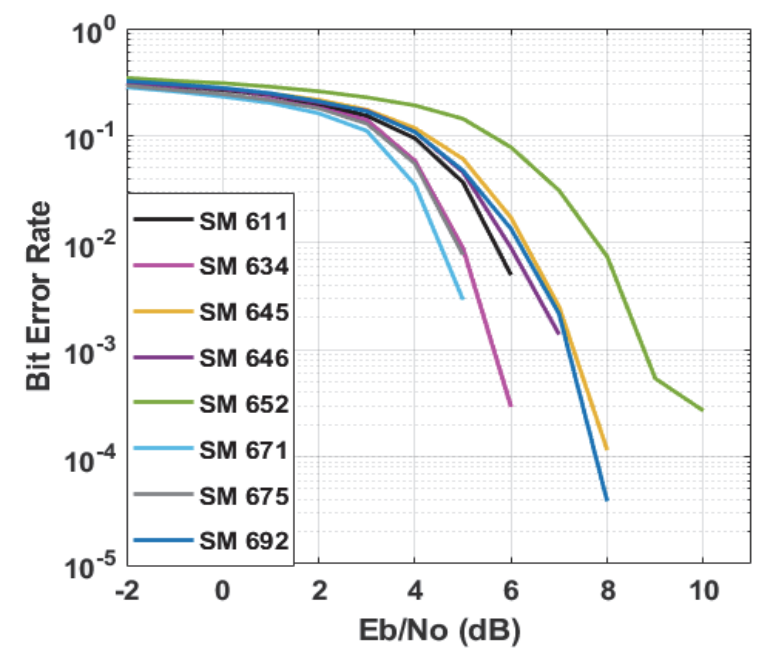

Fig. 4. SMs transport blocks - BER performance of LDPC coding scheme for Rayleigh channel $($ code rate $=1 / 2)$.

\section{CONCLUSION}

The potential of 5G-based real-time communication between SMs and Cloud platform in SG applications is revealed in this paper. Real-time communication enables Cloud-based online monitoring of power demand in SG. The capabilities of the developed 5G-based real-time communication model are demonstrated using the case study of the power demand variation scenario in a wellknown IEEE 13 node network. Online monitoring of power demand by the remote reading of SMs proved to be very accurate in the 5G-based real-time communication modeling environment. Additional testing related to BER performance analysis reveals that the proposed communication system model performs very accurately even for low $\mathrm{E}_{\mathrm{b}} / \mathrm{N}_{0}$ values. The possible applications of the proposed Cloud-based system in SG are enormous. AMI could be significantly empowered using the proposed approach. Besides power demand, online monitoring could be applied to predictive maintenance of power system components, power quality related metrics, and fault management systems.

\section{REFERENCES}

[1] NETL, "A vision for the smart grid," 2009, Available: https://netl.doe.gov/sites/default/files/Smartgrid/Whitepaper_TheModern-Grid-Vision_APPROVED_2009_06_18.pdf

[2] M. Forcan and $\bar{M}$. Maksimović, "Fog Computing-Based Communication Systems for Modern Smart Grids," in Fog Computing: Theory and Practice, Wiley, pp. 347-369, 2020., doi: 10.1002/9781119551713.ch13.

[3] S. R. S., T. Dragičević, P. Siano and S.S. Prabaharan, "Future Generation 5G Wireless Networks for Smart Grid: A Comprehensive Review," in Energies 12, no. 11: 2140, 2019, doi:10.3390/en12112140.

[4] M. Forcan and M. Maksimović, "Cloud-Fog-based approach for Smart Grid monitoring," in Simulation Modelling Practice and Theory, vol. 101, 2020, 101988, https://doi.org/10.1016/j.simpat.2019.101988

[5] M. Forcan, M. Maksimović, J. Forcan, and S. Jokić, "5G and Cloudification to Enhance Real-Time Electricity Consumption Measuring in Smart Grid," 28th Telecommunications Forum (TELFOR), Belgrade, pp. 1-4, 2020, doi: 10.1109/TELFOR51502.2020.9306518.

[6] E. J. Palacios-Garcia et al., "Using smart meters data for energy management operations and power quality monitoring in a microgrid," 2017 IEEE 26th International Symposium on Industrial Electronics (ISIE), Edinburgh, pp. 1725-1731, 2017, doi: 10.1109/ISIE.2017.8001508.

[7] M. Campbell, N. Watson, A. Miller, "Smart Meters to Monitor Power Quality at Consumer Premises," EEA Conference \& Exhibition, Wellington, 24 -26 June 2015

[8] M. Maksimović, M. Forcan, "5G New Radio channel coding for messaging in Smart Grid," in Sustainable Energy, Grids and Networks, vol. $\quad 27, \quad 2021, \quad 100495$, https://doi.org/10.1016/j.segan.2021.100495.

[9] M. Yigit, V. C. Gungor, S. Baktir, "Cloud Computing for Smart Grid applications," in Computer Networks, vol. 70, pp. 312-329, 2014, https://doi.org/10.1016/j.comnet.2014.06.007.

[10] M. Forcan, M. Maksimović, J. Forcan, "Cloud-Based Approach for Real-time Monitoring of Smart Grid Topology," 5th Jubilee Virtual International Conference on Science, Technology and Management in Energy-eNergetics, pp. 47-54, 2019

[11] M. Gloukhovtsev, "How 5G transforms Cloud computing," Knowledge Sharing Article (C) 2020 Dell Inc. Available: https://education.dellemc.com/content/dam/dellemc/documents/enus/2020KS_Gloukhovtsev_How_5G_Transforms_Cloud_Computi ng.pdf

[12] M. Reeve, "The Cloud and 5G," Secura, 2019 Available: https://secura.cloud/industry-insight/the-cloud-and-5g

[13] L. Alleyne, "The Impact of 5G on Cloud Computing," 2021, Available: https://www.itbusinessedge.com/mobile/the-impact-of5g-on-cloud-computing/

[14] Enabling Smart Energy as a Service via 5G Mobile Network advances - Final 5G Network Architecture to Support Smart Energy, Project: H2020-ICT-07-2017, Available: https://ec.europa.eu/research/participants/documents/downloadPub lic?documentIds $=080166 \mathrm{e} 5 \mathrm{~cd} 3 \mathrm{~b} 7 \mathrm{ad} 6 \&$ appId=PPGMS

[15] MATLAB, 2020. version R2020a, Natick, Massachusetts: The MathWorks Inc.

[16] IEEE Standard for Utility Industry Metering Communication Protocol Application Layer (End Device Data Tables), in IEEE Std 1377-2012 (Revision of IEEE Std 1377-1997), vol., no., pp.1-576, 10 Aug. 2012, doi: 10.1109/IEEESTD.2012.6264065

[17] 3GPP TS 38.212 V15.8.0 (2019-12) 3rd Generation Partnership Project; Technical Specification Group Radio Access Network; NR, Multiplexing and channel coding (Release 15)

[18] E. Biglieri, "Fading channels". In: Coding for Wireless Channels. Information Technology: Transmission, Processing and Storage. Springer, Boston, MA, 2005. https://doi.org/10.1007/1-4020-8084$0 \_4$,

[19] ThingSpeak, Available: https://thingspeak.com/

[20] IEEE 13 Node Feeder, Available: https://site.ieee.org/pestestfeeders/resources/ 